outcome but the one that produces the outcome that the patient favours. When patients are mentally incompetent an advance directive may express their wishes. Having ascertained that the directive was made in the light of knowledge of the medical facts and a clear understanding of the implications, doctors should be morally and legally obliged to respect the patient's wishes.

The concern that developments in treatment will not be accommodated is unrealistic. Sudden cures for incurable diseases are regrettably rare. If a previously untreatable disease became treatable, however, I believe that the courts would support a doctor who disregarded an advance directive drawn up before the treatment was available.

A more regular occurrence in my practice is that I wish to know an unconscious patient's views on what is an acceptable quality of life, given that he or she is now critically ill in an intensive care unit. Often the best we can achieve is survival with severe neurological damage or other impairment. Once we have ensured survival with aggressive, unpleasant, and costly treatment and have delivered a quality of life that is unacceptable to the patient neither we nor the patient can undo the harm.

An increasing number of patients express their wishes about limitation of treatment before their admission to our unit. Often they are former patients who found the quality of life on discharge barely acceptable and cannot contemplate survival with additional physical or mental impairment. I am happy to respect those wishes, as I would like my wishes to be respected were I in that position. I see no difference between this scenario and that of a Jehovah's Witness who refuses a blood transfusion-a situation in which the law and medical ethics are quite clear. ${ }^{2}$ When a patient's wishes require a doctor to act contrary to his or her conscience the doctor must refer the patient to another practitioner. The alternative, of doctors carrying out treatments contrary to the patient's stated wishes and getting away with it because the patient is not mentally or physically competent to resist, is something that no doctor or the BMA could sanction.

SIMON FINFER

Royal North Shore Hospital,

Specialist in intensive care

Intensive Therapy Unit,

St Leonards,

St Leonards,

Australia

1 Jessiman IMCD. BMA division disagrees with association's stance over advance directives. BMf 1996;312:850-1. (30 March.)

2 Finfer S, Howell S, Miller J, Willett K, Wilson-MacDonald J, Wilson $\mathrm{DH}$, et al. Managing patients who refuse blood transfusions: an ethical dilemma. BMf 1994;308:1423-6.

\section{Coffee intake and death from coronary heart disease}

\section{Coffee may have both short and long term effects}

EDrTOR,-I Stensvold and colleagues found that a previously reported association between coffee consumption and mortality from coronary heart disease had been weakened by six more years of follow up, and they suggest that this could be due to a decreased intake of boiled coffee. ${ }^{1}$ When, however, they excluded subjects who were referred to a doctor because of their coronary risk, and when they analysed more than 23000 subjects included some years later in an identical study (thus using a more recent evaluation of the distribution of risk factors), the coefficient for coffee drinking was slightly higher.

Between 1990 and 1992 we performed two case-control studies in patients with first confirmed acute myocardial infarction and ischaemic stroke

Table 1-Odds ratio of myocardial infarction and ischaemic stroke according to daily coffee intake

\begin{tabular}{|c|c|c|c|c|}
\hline \multirow[b]{2}{*}{$\begin{array}{l}\text { Daily coffee intake } \\
\text { (cups) }\end{array}$} & \multicolumn{2}{|c|}{ Myocardial infarction } & \multicolumn{2}{|c|}{ Ischaemic stroke } \\
\hline & Cases/controls & $\begin{array}{c}\text { Odds ratio* } \\
\text { (95\% confidence } \\
\text { interval) }\end{array}$ & Cases/controls & $\begin{array}{c}\text { Odds ratio* } \\
\text { (95\% confidence } \\
\text { interval) }\end{array}$ \\
\hline 0 & $56 / 97$ & 1.0 & $57 / 57$ & 1.0 \\
\hline 1 & $91 / 134$ & 1.0 & $61 / 80$ & $0.6(0.3$ to 1.2$)$ \\
\hline 2 & $121 / 156$ & $1.1(0.6$ to 1.8$)$ & $63 / 59$ & $1.4(0.7$ to 2.8$)$ \\
\hline 3 & $90 / 59$ & $1.9(1.0$ to 3.4$)$ & $30 / 25$ & $0.7(0.3$ to 1.7$)$ \\
\hline 4 & $66 / 32$ & $2.9(1.3$ to 6.5$)$ & $10 / 14$ & $0.6(0.2$ to 1.7$)$ \\
\hline$\geqslant 5$ & $89 / 35$ & $3.8(1.8$ to 7.9$)$ & $16 / 2$ & $15.3(2.4$ to 97.5$)$ \\
\hline
\end{tabular}

*Conditional multiple logistic model adjusted for social class, education, alcoholic beverages, smoking habit, diabetes mellitus Conditional multiple logistic model adjusted for social class, education, alcoholic beverages, smoking habit, diabetes mellitus,
hypertension, blood cholesterol concentration, body mass index, physical activity, and family history of myocardial infarction and hypertensic
stroke.

confirmed by computed tomography; these were conducted in parallel and with the same operational characteristics (same hospitals, interviewers, etc) in Abruzzo (southern Italy). Altogether 513 patients with acute myocardial infarction (median age 58) and 237 with ischaemic stroke (median age 63) were recruited along with hospital controls (matched by five year age group and sex) with acute diseases not related to cardiovascular risk factors. Our results (table 1) accord with those of a recent meta-analysis ${ }^{2}$ and with the first six years of follow up in Stensvold and colleagues' cohort study and support the existence of a short term effect of coffee intake. No clear relation could be found between coffee intake and ischaemic stroke, possibly because of the low number of subjects with high levels of coffee consumption who were older. In Greenland's meta-analysis recent cohort studies had more positive results than older ones, while a fairly homogeneous increased risk was found in case-control studies. ${ }^{2}$

Cohort studies cannot easily allow for the changes in lifestyle habits that occur during follow up: coffee intake peaks between ages 40 to 49 and then declines, ${ }^{3}$ and assessment of coffee consumption 10 or more years before death from coronary heart disease may be a poor indicator of more recent consumption. ${ }^{4}$ In addition, non-fatal cardiovascular events (for example, acute myocardia infarction, angina pectoris, revascularisation procedures) could result in patients stopping smoking as well as reducing their coffee intake. The effect of coffee intake in Stensvold and colleagues' study (this information was collected at baseline) could therefore have been weakened as follow up was prolonged.

In summary, the existence of a short term effect of coffee intake in addition to a long term one (on atherosclerosis) cannot be easily dismissed. Negative results of cohort studies could be associated with a modification of lifestyle habits (including stopping drinking coffee and lowering intake in addition to changing the type of coffee consumed), due either to aging of the cohort or a worsening health status during follow up.

This work was supported by the Italian National Research Council (Convenzione CNR Consorzio Mario Negri Sud).

ROBERTO MARCHIOLI Senior investigato
ROCCO DI MASCIO Consultan

ROSA MARIA MARFIS Research assistan FELICE VITULLO Research assistan GIANNI TOGNONI Head of department On behalf of the Progetto 3A Investigators Department of Clinical Pharmacology and Epidemiology, Istituto di Ricerche Farmacologiche Mario NegriConsorzio Mario Negri Sud, Santa Maria Imbaro (Chieti),

Italy

1 Stensvold I, Tverdal A, Jacobsen BK. Cohort study of coffee intake and death from coronary heart disease over 12 years. BMF 1996;312:544-5. (2 March.)
2 Greenland $\mathrm{S}$. A meta-analysis of coffee, myocardial infarction, and coronary death. Epidemiology 1993;4:366-74

3 Christensen L, Murray T. A review of the relationship between coffee consumption and coronary heart disease. $9 \mathrm{Com}-$ munity Health 1990;15:391-408.

4 Franceschi S. Coffee and myocardial infarction: review of epidemiological evidence. In: Garattini S, ed. Caffeine, coffee, and health. New York: Raven Press, 1993:195-211.

Coffee drinking was compared with tea drinking in monozygotic twins in 18th century

EDITOR,-One of the more peculiar attempts to throw light on the question of whether drinking coffee is bad for one's health ${ }^{1}$ was carried out in the 18th century by King Gustaf III of Sweden. $\mathrm{He}$ is better known for instituting the Swedish Academy, the august body of 18 (18 because the king liked the sound of the Swedish word for that number, ardeton) whom Alfred Nobel later selected to award his prize in literature.

A pair of monozygotic twins had been sentenced to death for murder. Gustaf III commuted their death sentences to life imprisonment on the condition that one twin drank a large bowl of tea three times a day and that the other twin drank coffee. The twin who drank tea died first, aged 83-a remarkable age for the time. Thus the case was settled: coffee was the less dangerous of the two beverages. The king, on the other hand, was murdered at a masked ball in 1792 at the age of 45 and became the subject of an opera by Verdi.

ARS BREIMER Clinical lecturer

Department of Chemical Pathology and Human Metabolism, Royal Free Hospital School of Medicine London NW3 2QG

1 Stensvold I, Tverdal A, Jacobsen B. Cohort study of coffee intake and death from coronary heart disease over 12 years. $B M F$ 1996;312:544-5. (2 March.)

\section{Care management}

\section{Care programme approach constitutes} good management

EDITOR,-Max Marshall is correct in distinguishing between "standard" case management and "assertive community treatment." Clearly, the benefits suggested by research on assertive community teams cannot be expected for routine community teams, which have lower ratios of staff to patients. This does not mean, however, that the care programme approach offers no benefits to patients and their relatives. It is hard to see how the components of the care programme approach can be regarded as anything but good practice for people with a mental illness. Surely patients should have their needs assessed and care plans recorded. And, surely, any care that is instigated should be reviewed and there should be one professional 
who monitors the care plan and to whom the patient and relatives can turn. These principles of care are appropriate for mildly depressed patients seeing one doctor in an outpatient clinic as well as for a patient with severe schizophrenia who sees several professionals.

I believe that the current frustrations with the care programme approach have arisen largely because it has highlighted the fact that, in many areas, good practice is impossible to implement owing to insufficient resources. All too often mental health services offer little more than reactive, crisis driven care, with their high staff turnover making continuity of care an impossible aspiration. The care programme approach is helping to show the true picture of mental health services, and it is not a pretty picture.

Marshall points out that a recent controlled trial reported a doubling of admissions to hospital after the introduction of the care programme approach. ${ }^{2}$ Rather than being interpreted as a failure of the approach, this may indicate that the approach is doing its job-that is, helping services maintain contact with patients and drawing attention to unmet need, including the need for admission to hospital. It is oversimplistic to regard admission to hospital as a measure of failure.

It is easy to criticise the care programme approach, but can anyone suggest a better way of developing proactive and comprehensive mental health services into the next century?

\section{MICHAEL PHELAN}

Department of Psychiatry,

Charing Cross Hospital,

London W6 8RU

1 Marshall $M$. Case management: a dubious practice. $B M \mathcal{Y}$ 1996;312:523-4. (2 March.)

2 Tyrer P, Morgan J, van Horn E, Jayakody M, Evans $K$ Brummell $\mathrm{R}$, et al. A randomised controlled study of close monitoring of vulnerable psychiatric patients. Lancet 1995;345:756-9.

\section{Case management confers substantial}

\section{benefits}

EDITOR,-Max Marshall claims that case management is "a dubious practice...underevaluated and ineffective....bedevilled by a tendency to lump two different approaches under one name." $\mathrm{He}$ then bedevils it further by equating care programming with "standard" case management, and what is frequently referred to in the American literature as case management as "assertive community treatment." In a recent editorial on the subject in the Lancet "case" and "care" were used interchangeably. ${ }^{2}$

These terms are not difficult to distinguish, and much is to be achieved by distinguishing them. The meaning of case management evolved rapidly, reflecting the context in which it operated and increasing understanding of its working. Initially the focus was on the coordination of care and obtaining access to support and benefits by an office based administrator, who often had no health or social services background. This model ("brokerage case management") was soon recognised to be of limited value in serious mental illness, and this was confirmed by controlled studies. ${ }^{3}$ Case managers shifted their emphasis to more direct care ("full support" or "clinical case management"), which has become the dominant approach in the United States.

Clinical case management increasingly emphasises outreach, small caseloads, and a broad clinical remit. Consequently, the term is now virtually synonymous with what is done by the assertive community treatment team (itself a concept that evolved from "training in community living"). These teams have been subjected to over 13 randomised controlled trials, which have overwhelmingly shown their value. ${ }^{4}$

The research evidence is therefore clear and unusually abundant. Brokerage case management (renamed care management in British social services) is costly, with no added benefits for patients, ${ }^{35}$ and its adoption as policy in England threatens to damage mental health social work severely. ${ }^{2}$ Case management (clinical case management) has been extensively researched and confers substantial benefits.

Use of the care programme approach with long term and complex problems arises logically from the philosophy of case management, is clinically coherent, and generates little controversy. Insistence that every patient of the menta health services should be included in this approach is a bureaucratic diktat that perpetuates confusion over whether it is clinically derived practice or an administrative procedure.

All three processes have a clear clinical identity. For two of them adequate evidence exists to make informed decisions about their value. For the care programme approach clinicians need to take responsibility for shaping and researching it. Administratively coherent but clinically nonsensical definitions should not be allowed to confuse thinking or determine practice.

St George's Hospital Medical School,

Department of Mental Health Sciences,

London SW 17 ORE

1 Marshall M. Case management: a dubious practice. BMY 1996;312:523-4. (2 March.)

2 Care-management: a disastrous mistake [editorial]. Lance 1996;345:399-401.

3 Franklin JL, Solovik B, Mason M, Clemons JR, Miller GE. An evaluation of case management. Am $\mathcal{f}$ Public Health 1994;77:674-8.

4 Solomon P. The efficacy of case management services for severely mentally disabled clients. Community Ment Health $\mathscr{f}$ 1992;28:163-80.

5 Marshall M, Lockwood A, Gath D. Social services case-management for long-term mental disorders: randomised controlled trial. Lancet 1995;345:409-12.

\section{Administrative demands of care} programme approach

EDITOR,-Max Marshall makes the point that the care programme approach has never been fully evaluated, and that its American counterpart, case management, has not proved to be a particularly successful approach. ${ }^{1}$ In Britain, some studies have claimed that the approach is successful-for example, in tailoring care to individual needs-whereas others have shown that care programme approach fails to improve outcome and has no effect on rates of suicide or reoffending. ${ }^{2} 3$

We investigated the implementation of this approach within a mental health trust, studying administrative demands and the opinions of practitioners regarding the potential benefits and problems. Our results suggest that the care programme approach increases workload disproportionately to its perceived benefits. The most commonly cited problems included increased demands of time and workload due to extra administrative tasks and, perhaps more worryingly, the consequent detraction from time available to spend with patients.

The same issues were highlighted in the observational component of the study, using a multidisciplinary team meeting. These meetings are now required to discuss and review the care plans and complete the associated paperwork for all clients, but data from one such meeting indicates that this may not actually be feasible or appropriate in terms of time and human resources. In the one meeting studied, $110 \mathrm{~min}$ utes were spent discussing matters generated solely by the care programme approach Fourteen practitioners were present, so this amounted to a total of 1540 minutes (25.7 hours) of extra staff time. Previously the average meeting time was 60 minutes; this meeting was 170 minutes long. Practitioners had accommodated this added time commitment by cancelling ward rounds and community visits. Therefore, 25.7 hours of time had been effectively taken away from patients. During this time, only 13 patients were discussed.

In a trust currently dealing with over 7000 open cases, our preliminary results. suggest that the demands the care programme approach puts on the system are logistically impractical, if not impossible.

It seems ironic that, in the current climate of evidence based medicine, the care programme approach continues to be not only advocated but enforced, despite a lack of supporting evidence for its usefulness. It would seem that this approach is being pursued so relentlessly because of its status as a government policy, rather than on its own merit.

CLAIRE EASTON Research officer FEMI OYEBODE Consultant psychiatrist

Research and Development Unit,

Queen Elizabeth Psychiatric Hospital,

Edgbaston,

Birmingham B15 2QZ

Marshall $M$. Case management: a dubious practice. $B M \mathcal{F}$ 1996;312:523-4. (2 March.)

2 Shepherd G, King C, Tilbury J, Fowler D. Implementing the care programme approach. Fournal of Mental Health 1995; 4:261-74.

3 Pierides M, Craig T, Roy D. The CPA in West Lambeth: 3 year results. Proceedings of the winter meeting of the Royal College of Psychiatrists, 1996. London: Royal College of Psychiatrists, 1996.

\section{Continuing transmission of sexually transmitted diseases among patients infected with HIV}

\section{Qualitative study gave different results}

EDITOR,-M A Catchpole and colleagues report evidence of continued transmission of sexually transmitted diseases in homosexual and bisexual men infected with HIV-1. ${ }^{1}$ They reach several conclusions based on these findings, including that $(a)$ unsafe sexual practices are continuing in substantial numbers of such men; (b) only a minority of these cases of sexually transmitted diseases are likely to be due to long term infections, infections acquired during safer sexual practices, or infections acquired in relationships in which the partners are aware of their infectious status; and $(c)$ changes in sexual behaviour after the diagnosis of HIV infection are short lived or infrequent.

We recently completed a qualitative study of the sexual health of HIV positive homosexual and bisexual men; the results shed further light on the debate concerning the sexual practices of this group of patients. The study sample $(n=40)$ was recruited through community groups $(n=25)$ and HIV outpatient clinics $(n=15)$ covered by the Northern and Yorkshire Health Authority. All the men in our study reported regularly practising safer sex with casual partners and partners whose status was unknown or negative. Only three men reported isolated incidents of unsafe sex with casual partners or those of unknown serostatus after their own HIV infection was diagnosed. All other reports of unsafe sex $(n=8)$ occurred within regular relationships where the partner was also positive. Our participants typically reported that they 